Int. J. Dev. Biol. 53: 135-137 (2009)

doi: $10.1387 /$ ijdb.062266ss

\title{
Rotation in Xenopus laevis embryos during the second cell cycle
}

\author{
SERGEY M. STARODUBOV* and VLADIMIR A. GOLYCHENKOV \\ Department of Embryology, Biological Faculty, Moscow State University, Moscow, Russia
}

\begin{abstract}
Using time-lapse video recording and comparing successive digital images, we found that $38 \%$ of Xenopus laevis embryos $(n=118)$ exhibited rotation during the second cell cycle. This rotation, which we term the second rotation, started approximately during the appearance of the first cleavage furrow and proceeded clockwise or counterclockwise around the vertical axis. Rotations lasted for 5-30 minutes, i.e. up to the beginning of the third cell cycle. The mean rotation angle was $36.4^{\circ}$, with a maximum rotation of $77^{\circ}$. No mortality was observed among the embryos exhibiting rotation. The second rotation was observed to be similar to the well-known fertilization rotation which takes place during the first cell cycle. The possible nature and significance of the second rotation are discussed.
\end{abstract}

KEY WORDS: rotation, first furrow, second cell cycle, Xenopus

It is well known that during the first cell cycle of amphibian embryos, a prolonged rotation of the peripheral layer of the egg (its cortex) relative to the subcortical cytoplasm core takes place. This rotation, termed the fertilization rotation, appears to be necessary for bilateral symmetry formation in embryos (Clavert, 1962; Vincent et al., 1986; Gilbert, 2000). Here, we report that during the second cell cycle, some Xenopusembryos also exhibit a long-term rotation, which we call the second rotation. To the best of our best knowledge, this phenomenon has not yet been described. Therefore the aim of this work was to describe the second rotation for the first time and to offer suggestions about its nature and significance.

During the second rotation, it appears as if the whole embryo rotates inside the perivitelline space; however, it cannot be ruled out that this rotation involves only the embryo cortex together with the first furrow. This rotation occurred clockwise or counterclockwise around a vertical axis (Fig. 1 A-D). These rotations were observed in embryos obtained by either natural or artificial fertilization, including direct artificial fertilization in the chamber without further embryo manipulations. Rotations usually started 1-2 min after the appearance of the first furrow, but sometimes occurred simultaneously with or 1-2 min before the onset of the first furrow (when rotations started earlier than furrow onset, rotation measurements were impossible because the embryos surface had no constant marks). The duration of rotations was 5-30 min after the appearance of the first furrow, i.e. some rotations can persist during the entire second cycle until the appearance of the second furrow. Small rotations which lasted less than 4-5 min were not considered further in this study.

In an initial series of experiments to quantify the angle of rotation, we used 25 rotating embryos taken from 11 batches. The mean rotation angle was $36.4 \pm 13.0^{\circ}$ (range: $14.5-77^{\circ}$ ). Next, we carried out additional observations on embryos from three large, independent batches in order to quantify the percentage of embryos exhibiting rotation. A total of 118 embryos were studied; the mean percentage of embryos that exhibited rotation was $38.0 \pm 12.2 \%$ (range: $30-52.1 \%$ ), and $57.5 \%$ and $42.5 \%$ of rotations were clockwise and counterclockwise, respectively. These data obviously point to the absence of a dominant direction of rotation.

In embryos exhibiting rotation, no noticeable anomalies were found during the following 4-6 hours in three experiments. An additional experiment was performed to assess the viability of embryos with rotation. Seven embryos that exhibited rotation and 19 embryos which did not present rotation, both groups being from the same batch, were observed for longer period of time. Within several hours, only two of the embryos which had not exhibited rotation died, while the remaining embryos in both groups continued their development and successfully passed hatching in two days.

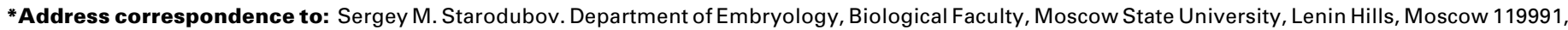
Russia. Tel: +7-495-939-39-00. Fax: +7-495-939-43-09. e-mail: starodub@gol.ru or starodubov@gmail.com
}

Supplementary Material for this paper is available at: http://dx.doi.org/10.1387/ijdb.062266ss

Accepted: 4 April 2008. Published online: 6 November 2008

ISSN: Online 1696-3547, Print 0214-6282

() 2008 UBC Press

Printed in Spain 

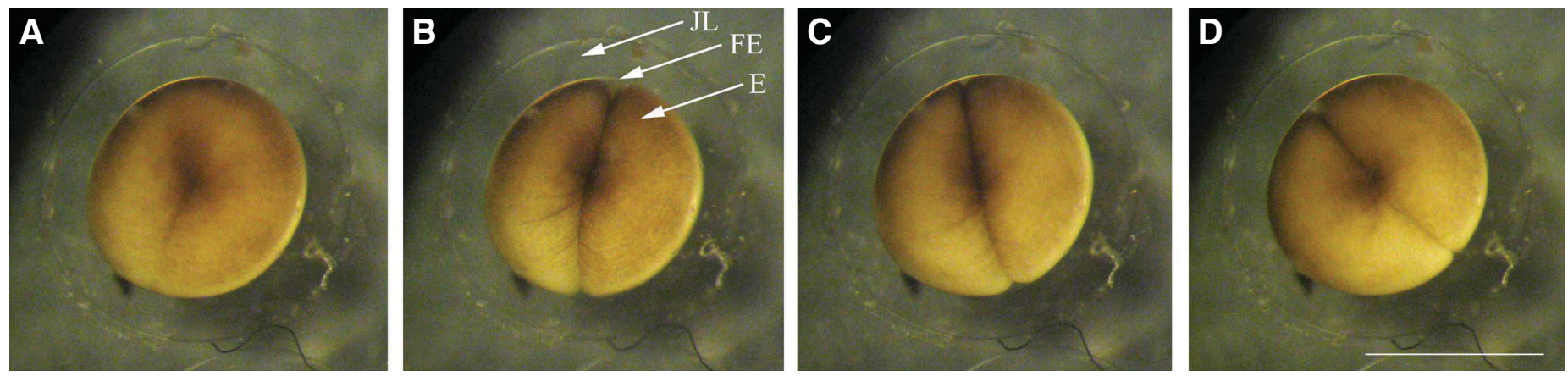

Fig. 1. Rotation in a Xenopus laevis embryo after the appearance of the first cleavage furrow. This rotation (A-D) takes place inside the perivitelline space counterclockwise around the vertical axis, to about $60^{\circ}$, and lasts from the appearance of the first furrow until the appearance of the second furrow. (A) $1 \mathrm{~min}$, (B) $6 \mathrm{~min}$, (C) $12 \mathrm{~min}$ and (D) 29 min after the first furrow appearance; the second furrow appeared 1-2 min after the stage shown in (D). The embryo inner jelly layer (JL) is seen on the outside of an embryo (E); the outer jelly layer had been removed with needles. The fertilization envelope (fe) is seen near the upper edge of the furrow $(B, C)$. The very thin perivitelline space is located between an embryo and the fertilization envelope. Bar, $1 \mathrm{~mm}$.

In one group of eight embryos the kinematics of rotation was determined. In most cases $(n=6)$, the kinematics of angular rotation was very well described by a logistic curve (Fig. 2A). Using mathematical differentiating of the angular rotation curves we obtained the proper angular rotation velocity curves. The velocity was not constant; the maximum angular rotation was 1.79 degree/min. As shown in Fig. 2B, the maximum angular rotation velocity was found to be near the moment of appearance of the first furrow and then this velocity gradually declined. The calculations revealed that maximum values of embryo surface rotation velocity ranged from 18.8-99.7 $\mu \mathrm{m} / \mathrm{min}$ (for embryos with an average diameter of $1.27 \mathrm{~mm}$ ).

It is informative to compare the second rotation which we observed in Xenopus laevisembryos during the second cell cycle with the fertilization rotation which takes place during the first cell cycle. The fertilization rotation takes place after the first DNA synthesis (Ubbels et al.,1983; Vincent etal.,1986) and the second rotation in our experiments evidently occurs after the starting of the second DNA synthesis (Ubbels et al.,1983). Both rotations are prolonged processes: fertilization rotation lasts for 30-40 min (Vincent et al., 1986) and the second rotation which we report here lasted for up to $30 \mathrm{~min}$. Both rotations appear after the ending of movements carried out by centrosome microtubules. Thus, fertilization rotation begins after pronuclei approach (Ubbels et al., 1983; Vincent et al., 1986) and the second rotation begins just after anaphase chromosome divergence (Ubbels et al., 1983). Before fertilization rotation commences, the sperm centrosome aster enlarges dramatically (Ubbels et al., 1983; Houliston and Elinson, 1991), and then centrosome microtubules are involved in producing this rotation (Elinson and Rowning, 1988; Houliston and Elinson, 1991). When the second rotation occurs after the appearance of the first cleavage furrow, large asters were observed around both sister centrosomes too (Takayama et al., 2002). These comparisons highlight the similarity of the fertilization and second rotation and suggest that centrosome microtubules may take part in the mechanism of second rotation also.

Fertilization rotation consists of rotation of the egg cortex relative to its subcortical cytoplasm core (Vincent et al., 1986). It is currently unknown if the second rotation which we report here is an authentic cortical rotation involving movement of the cortex relative to the underlying cytoplasm, or is merely the rotation of the whole embryo, similar to that which occurs during early amphibian development, due to the influence of gravity. Rotation under the influence of gravity, i.e. due to the force of gravity, occurs for the first time just after formation of the perivitelline space to orient the embryo with the lighter animal pole upwards (Clavert, 1962). Embryos subsequently retain the ability to rotate inside the perivitelline space to restore gravity equilibrium after any distur-
A

Fig. 2. Angle of rotation (A) and velocity of angular rotation (B) in one Xenopus laevis embryo as a function of time after the appearance of the first furrow. The kinematics of angular rotation is very well approximated by a logistic curve (A). It is clear that rotation underwent the bulk of its displacement within 10-15 minutes. The proper angular rotation velocity curve (B) was obtained by mathematically differentiating the angular rotation curve. As shown in (B), the maximum angular rotation velocity was found to be near the moment of appearance of the first furrow and subsequently, this velocity gradually declines.
B

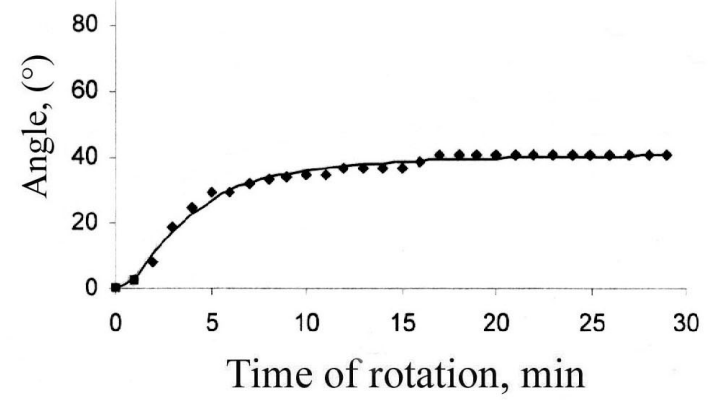


bance during the all cleavage period at least. Nevertheless, since gravity is a vertical force, it cannot account for the embryo rotation around a vertical axis which we observed during the second rotation.

Other evidence suggests that rotation during the second cycle may not be a cortical rotation. Thus, it is conceivable that the first cleavage furrow which arises on the embryo animal pole and then extends to the vegetal hemisphere could impede cortical rotation. However, this furrow is not very deep in most embryos, its depth on the animal pole reaching only about $25 \%$ of the egg diameter at the end of the second cycle (Nieuwkoop and Faber, 1956). Therefore, the appearance of the first furrow in most cases is unlikely to be able to impede cortical rotation during the second cycle. In addition, the very quick rise in the initial velocity of the second rotation (Fig. 2B) and the absence of reverse rotation are easier to explain in terms of rotation of a lightweight cortex rather than of a huge embryo. Experiments with vital labeling of cortex and subcortical cytoplasm, similar to those carried out by Vincent et al. (1986) will help to elucidate the nature of this second rotation.

Here we report that that some (38\%) Xenopusembryos exhibit rotation after the appearance of the first furrow, whereas the rest remained motionless. Such dynamic difference between embryos probably associated with the formation of some structural differences between them. For example, a different orientation of the first furrow relative to a "grey crescent" was identified at the beginning of the second cycle (Klein, 1987). Normally the first cleavage furrow bisects the grey crescent, and its plane is coincident with the plane of bilateral symmetry. However, the first furrow can deviate from the center of the grey crescent (Klein, 1987). It has generally been accepted that in this case, the plane of the first furrow does not coincide with the plane of bilateral symmetry. Klein (1987) revealed that the first furrow does not bisect the grey crescent in $30 \%$ of Xenopus laevis embryos, and deviation amplitude reaches $90^{\circ}$. In addition Klein (1987) did not find any anomalies in the embryos with furrow deviations. Thus, the second rotation which we report here has the surprising similarities with the first furrow deviation, including time of initiation (near the moment of the first furrow appearance), percentage of embryos with rotation (38\%) and maximum value of angular rotation (about $90^{\circ}$ ). It can therefore be reasonably hypothesized that the second rotation is a correction process which eliminates furrow deviations. Future studies will help to clarify this issue.

\section{Experimental Procedures}

Fertilized Xenopus laevis eggs were obtained by natural mating of adults induced by injection of human chorionic gonadotropin or by artificial fertilization as described elsewhere (Danilchik etal., 2003). In our experiments, we used either intact eggs, eggs without an outer jelly layer, having been removed with two needles, and eggs without either jelly layers, dissolved in $2.5 \%$ alkaline cysteine solution (cysteine chloride 2.5 $\mathrm{g}+\mathrm{NaOH} 0.92 \mathrm{~g}$ in $100 \mathrm{ml}$ of water). Eggs were usually transferred to dechlorinated tap water or to a 1/10 strength modified amphibian Ringer solution. Then video or digital photo recording of egg development was carried out usually up to the middle of the second cell cycle, and sometimes for an additional 4-6 hours more.

Time-lapse video recording (with 80 or 160 multiple reductions) was performed using a WV-CP610/g Panasonic Colour CCTV and Panasonic AG-6040 time-lapse tape. Successive digital images were obtained every 1-5 min with a 3.2 Mp Canon Powershot A70 Camera. A video camera without an objective or a digital camera with a Canon LA-DC52C adapter and additional self-made adapter was fixed on an MBS-10 stereomicroscope (Russia). A light source unit with a $50 \mathrm{~W}$ halogen lamp, a glass heat filter and two flexible guides was used.

Embryos exhibiting rotations were identified by playing back the tape or successive digital images. Successive contours of such embryos and their furrows were superposed and the rotation angles were measured. The results were processed using SigmaPlot software and graphs were plotted using Excel software.

\section{Acknowledgements}

The authors wish to thank Dr. YuriK. Doronin for discussions and help with graph plotting and Dr. Igor A. Kasevich (Invertebrate Zoology Department) for the use of his time-lapse tape recorder.

\section{References}

CLAVERT, J. (1962). Symmetrization of the egg of vertebrates. Adv. Morph. 2: 2760.

DANILCHIK, M. V., BEDRICK, S. D., BROWN, E. E. and RAY, K. (2003). Furrow microtubules and localized exocytosis in cleaving Xenopus laevis embryos. J. Cell Sci. 116: 273-283.

ELINSON, R.P. and ROWNING, B. (1988). A transient array of parallel microtubules in frog eggs: Potential tracks for a cytoplasmic rotation that specifies the dorso-ventral axis. Dev. Biol. 128: 185-197.

GILBERT, S. F. (2000). Developmental Biology, 6th ed., Sinauer Associates, Inc., Publishers, Sunderland, M.A., (USA), 749 p.

HOULISTON, E. and ELINSON, R.P. (1991). Patterns of microtubule polymerization relating to cortical rotation in Xenopus laevis eggs. Development112: 107117.

KLEIN, S.L. (1987). The first cleavage furrow demarcates the dorsal-ventral axis in Xenopus embryos. Dev. Biol. 120: 299-304.

NIEUWKOOP, P. D. and FABER, J. (1956). Normal table of Xenopus laevis (Daudin). North-Holland Publ., Co., Amsterdam, 243 p.

TAKAYAMA, M., NOGUCHI, T., YAMASHIRO, S. and MABUCHI, I. (2002). Microtubule organization in Xenopus eggs during the first cleavage and its role in cytokinesis. Cell Struct. Funct. 27: 163-170.

UBBELS, G. A., HARA, K., KOSTER, C. H. and KIRSCHNER, M. W. (1983). Evidence for a functional role of the cytoskeleton in determination of the dorsoventral axis in Xenopus laevis eggs. J. Embryol. Exp. Morphol. 77: 15-37.

VINCENT, J. P., OSTER, G. F. and GERHART, J. C. (1986). Kinematics of gray crescent formation in Xenopus eggs: the displacement of subcortical cytoplasm relative to the egg surface. Dev. Biol. 113: 484-500. 


\section{Further Related Reading, published previously in the Int. J. Dev. Biol.}

See our recent Special Issue Fertilization, in honor of David L. Garbers and edited by Paul M. Wassarman and Victor D. Vacquier at: http://www.ijdb.ehu.es/web/contents.php?vol=52\&issue=5-6

See our recent Special Issue Limb Development edited by Juan Hurlé and Juan Carlos Izpisua Belmonte at: http://www.ijdb.ehu.es/web/contents.php?vol=46\&issue=7

Genetic control of floral size and proportions

Julia Weiss, Luciana Delgado-Benarroch and Marcos Egea-Cortines

Int. J. Dev. Biol. (2005) 49: 513-525

Regulation of gene expression by Pax6 in ocular cells: a case of tissue-preferred expression of crystallins in lens

Ales Cvekl, Ying Yang, Bharesh K. Chauhan and Kveta Cveklova

Int. J. Dev. Biol. (2004) 48: 829-844

PVF1/PVR signaling and apoptosis promotes the rotation and dorsal closure of the Drosophila male terminalia

Ana Macías, Nuria M. Romero, Francisco Martín, Leonardo Suárez, Alberto L. Rosa and Ginés Morata

Int. J. Dev. Biol. (2004) 48: 1087-1094

Origin and evolution of endoderm and mesoderm.

Ulrich Technau and Corinna B Scholz

Int. J. Dev. Biol. (2003) 47: 531-539

Type I cadherins are required for differentiation and coordinated rotation in Xenopus laevis somitogenesis.

Emiliana Giacomello, Jerome Vallin, Olivier Morali, Ivan S Coulter, Habib

Boulekbache, Jean $\mathrm{P}$ Thiery and Florence Broders

Int. J. Dev. Biol. (2002) 46: 785-792

Effect of genistein alone and in combination with okadaic acid on the cell cycle resumption of mouse oocytes.

A Van Cauwenberge and $\mathrm{H}$ Alexandre

Int. J. Dev. Biol. (2000) 44: 409-420

Cortical rotation is required for the correct spatial expression of $\mathrm{nr} 3$, sia and gsc in Xenopus embryos.

A Medina, S R Wendler and H Steinbeisser

Int. J. Dev. Biol. (1997) 41: 741-745

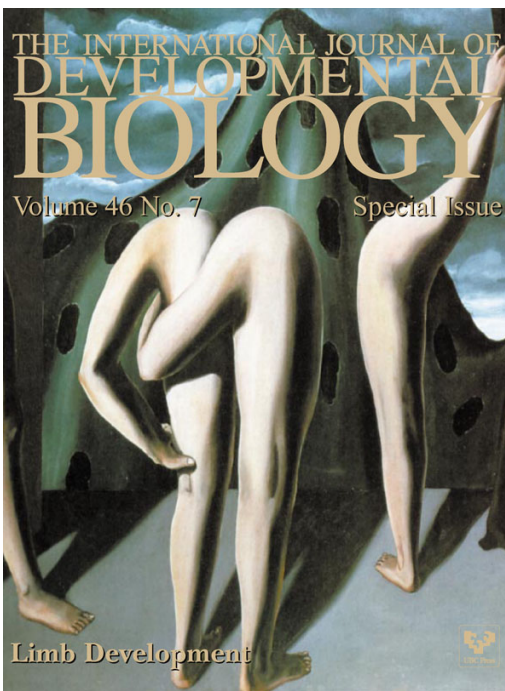

2006 ISI **Impact Factor $=3.577^{* *}$

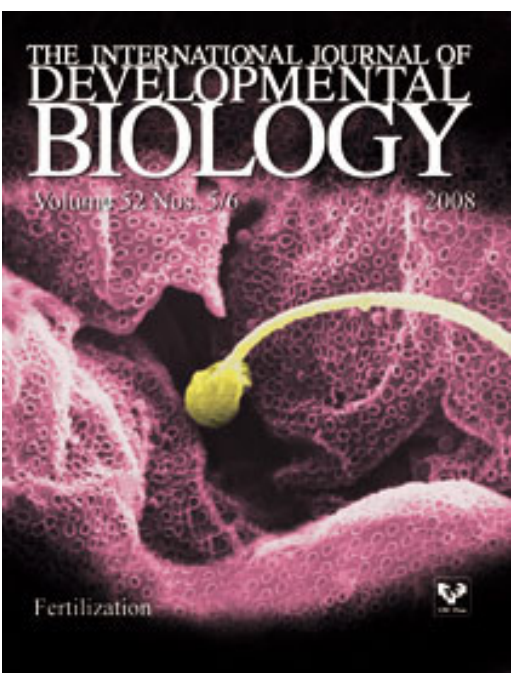

